\title{
Dr. Ernesto Frías Meneses. El primer anestesiólogo chileno
}

\author{
The first chilean anesthesiologyst: \\ Ernesto Frías Meneses M.D
}

\author{
Juan Pablo Álvarez'
}

"Nunca, en el ámbito del conflicto humano, hubo tantos que debieron tanto a tan pocos" Winston Churchill

E n cada generación de seres humanos existen algunos que, debido a las circunstancias a las que son expuestos deben buscar soluciones que, finalmente, los revelan como seres excepcionales. Ejemplos existen muchos. En todos los países y comunidades. Incluso sus gestas son cantadas por las generaciones siguientes y adornadas con nuevas visiones y apreciaciones de su actuar. Si están documentados, sus actos pasan a ser objeto de estudios y sus enseñanzas guían lo que se proyecta hacia el futuro.

Sin embargo, invariablemente durante su vida sufren de incomprensión por su entorno. Tal vez porque el foco de su visión está muchos años más allá de este presente mezquino que consume las preocupaciones más urgentes del día a día y que nos impide reflexionar sobre algo más que lo inmediato. De ahí nace la frase "nadie es profeta en su tierra", o la más criolla "el pago de Chile".

El Dr. Ernesto Frías Meneses fue un ser humano excepcional. Y como tal, sufrió también ese destino. Fue el iniciador de la anestesiología con base científica en Chile. No fue un académico como tal (no existía un departamento de anestesiología en ninguna de las universidades chilenas de la época), pero debido a interés, constancia y perseverancia hizo cosas que nunca nadie pensó que haría. Además, de estudiar, viajar, organizar el primer servicio de anestesiología de Chile, fundar la Sociedad Chilena de Anestesiología, crear la primera instancia en la que se enseñó anestesiología moderna y certificada en nuestro país, se dio tiempo para inventar e innovar, al desarrollar su propia versión de una máquina de anestesia en conjunto con una de las empresas líderes en el mundo en el desarrollo de equipamiento para anestesiología, la Foregger Company.

Por estas y muchas razones, la anestesiología nacional tiene una deuda con él. Reconocer sus aportes y logros, redescubrir sus intereses e ideas y tal vez buscar la manera de mantenerlo vivo en la memoria de los grandes médicos chilenos que llevaron a la medicina nacional a la situación que tanto orgullo nos produce hoy en día.

Los invito a revisar la vida del Dr. Frías, la raíz más antigua de la anestesiología organizada chilena.

Departamento de Anestesiología. Clínica Las Condes. Santiago, Chile.

* Palabras pronunciadas por el Primer Ministro Inglés Winston Churchill, el 16 de agosto de 1940 en referencia a la valentía y arrojo de los pilotos de la RAF en la defensa de la isla durante la batalla de Inglaterra ante las incursiones de los pilotos de la Luftwaffe.

Fecha de recepción: 14 de agosto de 2019

Fecha de aceptación: 18 de agosto de 2019

\section{ORCID}

https://orcid.org/0000-0003-3802-5484

Este artículo fue publicado en Revista Médica Clínica Las Condes, E. Frías, Rev. Med. Clin. Condes, sept-oct 2017, vol 28, num 5, con la debida autorización del autor y del Editor General de la Revista.

Email: jpabloalvarez@gmail.com 


\section{Anamnesis remota}

Ernesto Frías Meneses nació en Santiago de Chile el 16 de enero de 1908. Hijo de don Ignacio Frías Jara y doña Amelia Meneses Loyola. Al momento de nacer Ernesto, su padre ya tenía dos hijos mayores fruto de un primer matrimonio y cuatro hermanos mayores ( 3 hombres y una mujer) de su segundo matrimonio con doña Amelia. Con el paso de los años la familia se completaría con el nacimiento de 2 hijas más.

En esos años, la familia Frías Meneses tenía un buen pasar. Poseían una casa grande ubicada en la calle Catedral y en ella se desarrollaba la niñez de los hermanos Frías, incluyendo a los dos mayores que se integraron a esta dinámica familiar sin problemas.

Don Ignacio mantenía su numerosa familia manejando un negocio de compra y venta de mercadería e insumos para el hogar que manejaba desde Santiago, pero que le obligaba a salir cada 15 días a un pueblo cercano a la capital, Chiñihue (actualmente es parte de la comuna de El Monte, Talagante), en el que mantenía un emporio. Este negocio le aportaba el suficiente dinero para mantener a su familia y emprender iniciativas, pero lo obligaba a realizar un viaje de ida con mercadería, y uno de vuelta a Santiago con las ganancias obtenidas en dinero contante y sonante.

En las primeras décadas del siglo XX, las comunicaciones no eran tan expeditas como lo son hoy en día y el movimiento por los caminos estaba siempre amenazado por asaltantes que esperaban a sus víctimas en cualquier curva del camino. Transcurría la vida de la familia Frías Meneses sin grandes sobresaltos hasta que el año 1916 sucedió algo que cambiaría la vida de todo el clan. En una de las vueltas a Santiago desde su emporio en las afueras, don Ignacio fue víctima de un asalto. Le robaron todo el dinero que traía consigo. A pesar de haber sido brutalmente golpeado, logró ser llevado a su casa. Sin embargo, las lesiones fueron de tal magnitud que, aunque fue tratado por lo mejores médicos de la época, luego de unos meses, y a consecuencia de las agresiones sufridas, falleció en su domicilio. Ernesto contaba con 8 años.

\section{Etapa escolar}

De más está decir el gran impacto que esto produjo en la familia Frías Meneses. Repentinamente, el sustento estaba en peligro y el patrimonio familiar se vio reducido drásticamente. Se tuvo que vender la casa familiar de avenida Catedral para pagar los gastos médicos. La familia tuvo que trasladarse entonces a una casa más pequeña ubicada en un barrio

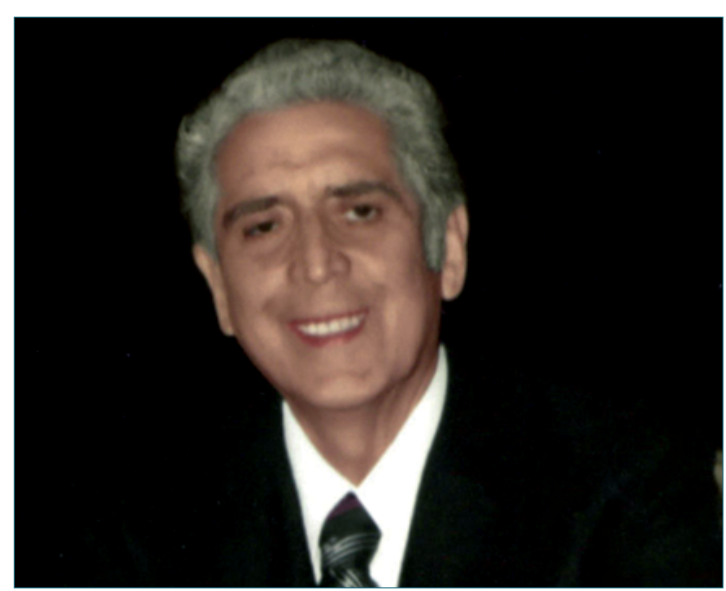

Figura 1. Dr. Ernesto Frías Meneses 1977.

menos central, al final de la calle Alameda. Así las cosas, Ernesto siguió sus estudios básicos que había comenzado en un colegio de los Hermanos Maristas. Se destacó como un niño inquieto y con buenas calificaciones. Una vez terminados sus estudios básicos, pasó al Liceo Manuel Luis Amunátegui, conocido como Liceo de Aplicación, para continuar sus estudios de humanidades. Durante su estadía en el liceo destacó por sus excelentes calificaciones y su mente inquieta.

Doña Amelia, la madre de Ernesto, tenía muchas preocupaciones, además, de organizar una casa y sacar adelante una familia. Este hijo, que era muy inquieto, la mantenía ocupada permanentemente.

Tenía una amiga muy cercana que era soltera y que además tenía una propiedad grande en la localidad de Peumo (actualmente es una comuna de la provincia de Cachapoal en la VI Región de O’Higgins). La Sra. Rosita, que así es como se la conocía en la familia, era además matrona, titulada en la Universidad de Chile. Tenía una gran conciencia social.

Recordemos que los hospitales aún eran regidos por juntas de beneficencia y el estado estaba en proceso de asumir sus responsabilidades como actor importante de la salud pública.

El caso es que, la Sra. Rosita, que no tenía hijos, recibía a Ernesto durante las vacaciones de verano para que tuviera algo que hacer.

Rosita no era una mujer lánguida. Era más bien muy activa y en su propiedad tenía una gran casa que había acondicionado como hogar de acogida para las mujeres embarazadas de la zona. Las recibía antes de parto, cuando estaban a punto de dar a luz, les atendía el parto y luego de dejarlas por 2 o 3 días, ellas volvían a su hogar con su hijo recién nacido. Ernesto se integraba a las actividades de la casa de Peu- 


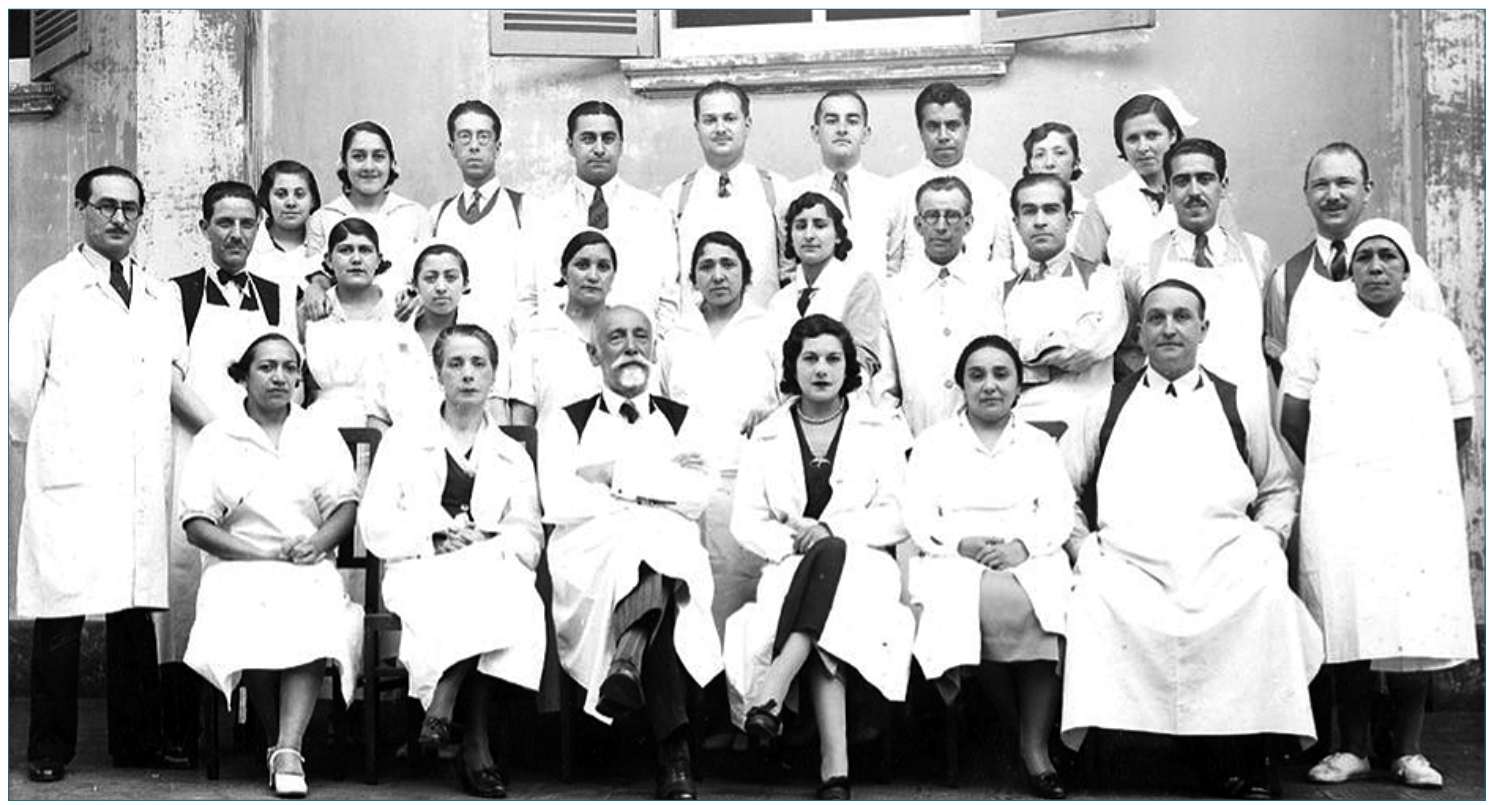

Figura 2. Dr. Frías como ayudante en la Clínica Quirúrgica del Prof. Dr. Lucas Sierra. Es el segundo de derecha a izquierda en la segunda fila (con permiso).

mo, pero como joven adolescente, poco intervenía en las actividades de la casa de acogida.

Con el tiempo, la gente del lugar comenzó a acudir a buscar atención no solamente relacionada con el parto, sino que de otras afecciones. Como esta faceta de atención fue creciendo, se constituyó una suerte de hospital rural al que llegó a trabajar un joven doctor de apellido Paredes.

Rosita vio en esto una oportunidad de darle una ocupación a este adolescente inquieto que pasaba los veranos en su casa. Y así fue como un día le presentó al Dr. Paredes a este joven que se convertiría en su ayudante. Ese fue el primer contacto con la medicina que tuvo el joven Ernesto y que definió su vocación. Una vez que conoció lo que hacía el Dr. Paredes, la atención que dedicaba a sus pacientes y cómo los sanaba, decidió que eso era lo que quería hacer el resto de su vida.

\section{La primera anestesia administrada por Ernesto Frías}

Mientras trabajaba como ayudante del Dr. Paredes en Peumo, contando con 16 o 17 años, aproximadamente en 1924, les avisaron de un accidente en un potrero cercano. Al llegar vieron a un obrero agrícola que estaba bajo un árbol.
Durante el proceso de tala y, debido a un mal cálculo, éste le había caído encima de una pierna. El Dr. Paredes, luego de examinar al paciente, tomo la decisión de realizar una amputación de la extremidad en el lugar del accidente. A Ernesto, como ayudante del doctor, le tocó la responsabilidad de eterizar al paciente para la exceresis de la extremidad. Le administró una anestesia por goteo con éter (la llamada "Anestesia de la Reina", utilizada desde 1876 y nombrada así porque el Dr. John Snow utilizó este sistema para asistir con anestesia el parto de la Reina Victoria de Inglaterra) bajo la supervisión del Dr. Paredes. La cirugía fue llevada a cabo con éxito y el paciente sobrevivió al accidente, a la cirugía y a la anestesia.

\section{Un accidente determinante}

Una vez decidida su vocación Ernesto siguió acudiendo los veranos a trabajar a Peumo como ayudante del Dr. Paredes. En 1926 atendió a un minero que llegó al hospital que falleció producto de complicaciones pulmonares asociadas a la silicosis. Además de atenderlo en la medida de lo posible, se encariñó con su paciente. Una vez que éste falleció, buscó entre sus pertenencias alguna dirección de familiares para darles la noticia de su muerte. Ahí encontró un par de detonadores de dinamita. Se dio cuenta de inmediato 


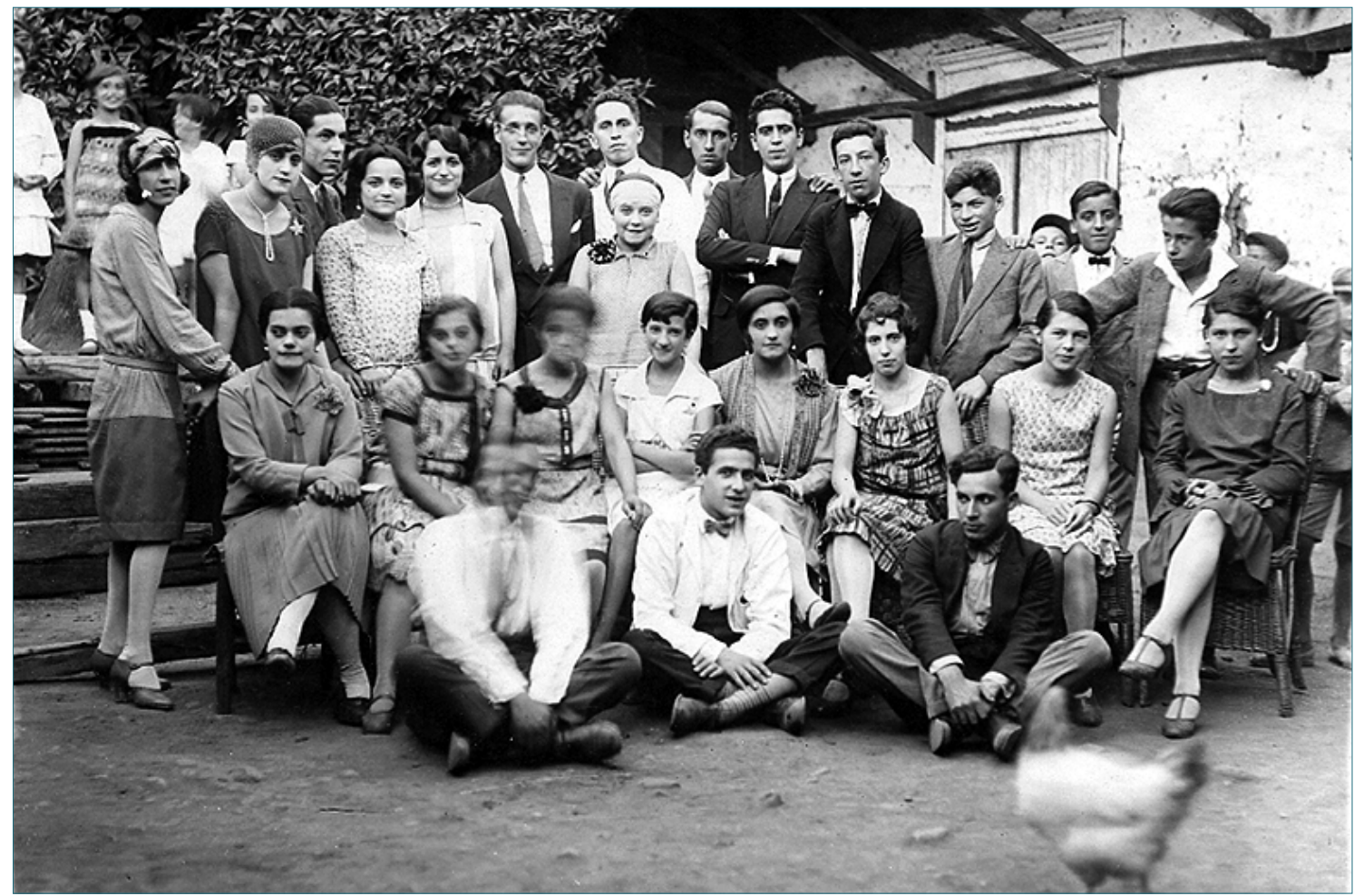

Figura 3. En Peumo durante su período de ayudante del Dr. Paredes. Es el séptimo de derecha a izquierda, en la última fila (con permiso).

del peligro que éstos representaban por lo que se dispuso a destruirlos.

Al llevarlos fuera de la casa para su destrucción, éstos le estallaron en las manos, por lo que perdió las primeras falanges de sus dedos pulgar e índice de la mano derecha.

Esto fue un gran golpe porque vio truncado su deseo de ser cirujano. Sin embargo, se sobrepuso e ingresó a estudiar medicina en 1927.

\section{Ante todo, un hombre práctico}

Antes de estudiar medicina y mientras estaba cursando sus humanidades Ernesto se inscribió en la Escuela Nocturna de Artes y Oficios con el fin de sacar un título que le permitiera ayudar con el mantenimiento familiar y de sus gastos. Durante los años 1924 y 1925 realizó con éxito los cursos para graduarse como técnico eléctrico. Así fue como aumentó sus exiguos recursos realizando reparaciones para conocidos, y no tanto, de los dispositivos eléctricos con que contaban. Una vez en la escuela de medicina, siguió ejerciendo este oficio hasta que el tiempo de estudio y las responsabilidades académicas no le dejaron tiempo.

\section{Estudiante de medicina y ejercicio temprano}

Ingresó a la Escuela de Medicina en 1927. Como dato curioso, fue compañero de Salvador Allende Gossens, quien muchos años después sería Presidente de Chile. Durante su carrera se le conoció como un estudiante trabajador y preocupado, con un gran sentido del humor. En 1933 se tituló de médico con la tesis "Resultados Alejados de las Simpatectomías Pelvianas" y comenzó a trabajar como ayudante en la prestigiosa clínica quirúrgica del Profesor Dr. Lucas Sierra. A través de la correspondencia que mantuvo con él se desprende que este maestro de la cirugía le tenía mucho cariño y respeto. Siempre le estimuló su interés y lo apoyó en sus intenciones de perfeccionarse en "el delicado arte de hacer insensibles a las personas" (sic).

En 1935, mientras trabajaba en la clínica del Dr. Sierra, consiguió ser aceptado en el Hospital Bellevue de Nueva York, el hospital público más antiguo de 


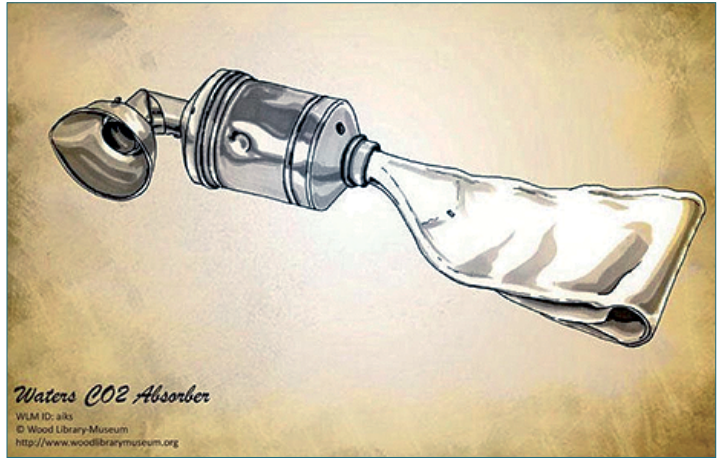

Figura 4. Canister de Waters o sistema "To and Fro" diseñado por el Dr. Ralph Waters (Tomado de https://www. woodlibrarymuseum.org/ museum/item/108/waters-co2absorber)

EE. UU. (fue fundado de 1736) y campo clínico de la NY School of Medicine, para conocer los adelantos en administración y seguridad en anestesiología. Fue un viaje iniciático.

\section{Primer viaje a Estados Unidos}

En 1935 Norteamérica estaba mucho más lejos de lo que está hoy en día. Un viaje así necesitaba no solamente tiempo, sino mucho más dinero. El Dr. Frías, como hombre práctico, solucionó este inconveniente contratándose como médico de navío a bordo de la marina mercante chilena. Como dato curioso, conoció a la poetisa Gabriela Mistral durante la travesía. Después de casi un mes de viaje, llegó a Nueva York y se presentó en el Bellevue. No encontramos registros sobre los médicos que conoció ni de las cirugías en las que participó. Pero sí sabemos que la razón que lo llevó a realizar este viaje fue el interés de aprender a realizar un nuevo tipo de anestesia general que se realizaba mediante el uso de sistemas de administración de anestésicos inhalatorios con circuito cerrado.

Aunque existían máquinas de anestesia en el país antes de 1935, éstas eran grandes y pesadas. Por otro lado, los circuitos eran abiertos (es decir, el paciente inhalaba el gas anestésico que una corriente de oxígeno llevaba disuelto y al exhalar, el mismo flujo se llevaba el dióxido de carbono que eliminaba el paciente hacia el ambiente) y en los grandes centros se estaba trabajando ya con los circuitos cerrados.

Estos circuitos son cerrados al ambiente y tienen un brazo inspiratorio y otro espiratorio. Por lo tanto, gran parte de lo que exhala el paciente es reinhalado en el próximo ciclo respiratorio.

\section{CHILEAN MIDGET}

The original design of Dr. Ernesto Frias of Santiago, Chile, is a 4yoke Mlidget, providing 3 control valves and 2 flowmeters, one for oxysen, one for eyclopropane, with one bi-pass valve for oxygen and one completely isolated bi.pass which may be used for nitrous oxide or carbon dioxide. The bi.pass valve for oxygen is interconnected with the control valve for oxygen, which permits the use of the second oxygen cylinder, thru the fowmeter.

A natural step in advance by providing control and flowmeter for Anesthetic gases in addition to the single Oxygen control of the Guedel Mlidget. The further modification of the original Chilean came through the demand for a flowmeter for nitrous oxide in addition to oxy gen and cyclopropane. Model 3 O.F.

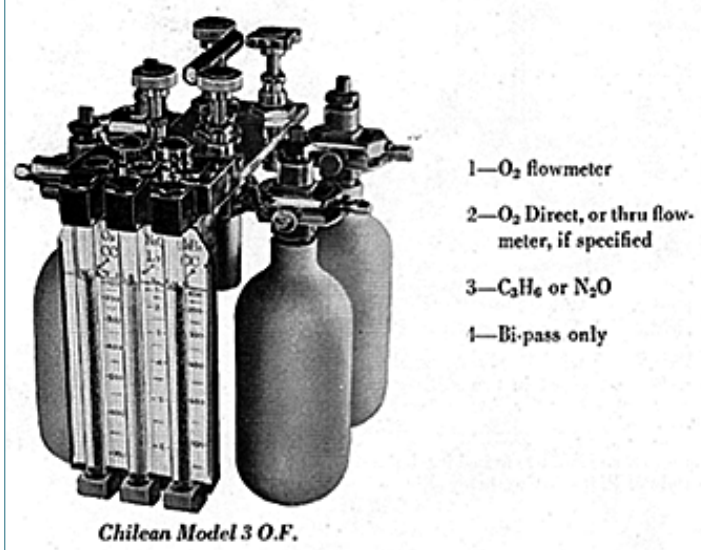

Prices, Chilesn Midget stripped, but including small accessories:

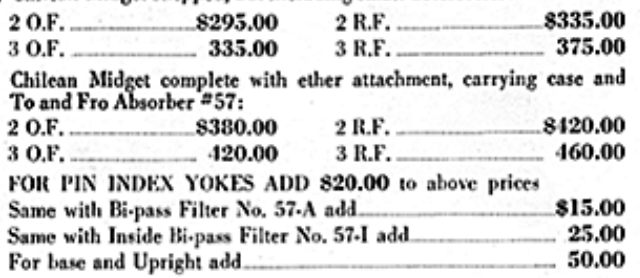

Figura 5. Foto de catálogo de la Foregger Company para la venta de la Chilean Midget.

Una de las grandes invenciones que permitió este avance fueron las sales absorbedoras de $\mathrm{CO}_{2}$. Estas hicieron que el $\mathrm{CO}_{2}$ que el paciente eliminaba en su respiración normal, fuera captado por ellas y luego de que el flujo de gases pasaba por el contenedor que las portaba, se podía volver a enviar al paciente el flujo de gases limpio de $\mathrm{CO}_{2}$ pero con oxígeno junto con el gas anestésico.

La existencia de estas sales no era nueva. De hecho ya se habían probado en la marina, durante la construcción de los primeros submarinos, pero su aplicación en medicina sí fue una novedad. Fue el Dr. Ralph Waters quien, a partir de 1919, desarrolló su sistema "To and Fro" que aprovechaba al máximo la absorción de dióxido de carbono. En pocas palabras era un cánister de sales absorbedoras asociado a una bolsa de ventilación y mascarilla facial. Todo en uno. 
Otros de los inventos que llevaron a los grandes avances de la anestesia y finalmente a la creación del circuito cerrado de administración de anestésicos inhalatorios, fueron la invención del tubo endotraqueal con cuff en 1931 y la pieza en $Y$ de Ayre para los circuitos abiertos descrita en 1937.

Las grandes ventajas del circuito cerrado frente a los circuitos abiertos son:

1. Permite utilizar bajos flujos, con los que se ahorra el gas anestésico.

2. Permite dar anestesia inhalatoria a presión positiva. Este hecho es especialmente importante para cirugía de tórax abierto ya que al abrir el tórax los pulmones se colapsan.

3. Disminuye la sequedad de mucosas y sus lesiones.

Así las cosas, la creación del circuito cerrado de anestesia estaba listo para ser creado y utilizado. Y en el momento en que el Dr. Ernesto Frías fue a Nueva York, todos estos avances estaban ocurriendo.

\section{La Chilean Midget}

En un artículo publicado en la revista Vida Médica en 1994 se lee "En el II Congreso Mundial de Anestesiología de 1960, un médico norteamericano se acercó al Dr. Raúl Mena para contarle..." "...Yo atravesé el Mediterráneo el día D como médico del ejército con una Chilean Model en la mano (sic)".

La Chilean Midget es una máquina de anestesia que fue pensada por el Dr. Frías desde una perspectiva de un país con pocos recursos (afirmación hecha por una de las hijas del Dr. Frías a mi persona, durante una entrevista).

Durante su estadía en EE.UU. tomó contacto con una de las empresas líderes en el desarrollo de equipamiento para anestesiología, la Foregger Company, empresa con la que mantendría una relación cercana para poder desarrollar el sistema anestésico que tenía en mente.

La Foregger Co. fue fundada en 1914 por Richard Von Foregger, un Doctor en Química, nacido en Austria en 1872 que se radico en Estados Unidos en 1902, luego de trabajar para diferentes compañías en Europa y en América. Durante ese tiempo, desarrolló y patentó un método para la producción de oxígeno a partir de peróxido de sodio. En 1907 conoció a James Tayloe Gwathmey, un médico que es considerado el padre de la anestesia moderna y que, entre todas sus actividades, desarrolló una máquina para la administración de gases anestésicos. Foregger inició su compañía con dos aparatos. Un generador de oxígeno y una máquina de anestesia (la Máquina de Gwathmey).
Pronto la Foregger Co. fue sinónimo de innovación en anestesiología, trabajando codo a codo con los distintos anestesiólogos clínicos que iban creando distintos dispositivos que se harían indispensables para la práctica anestésica moderna. Baste nombrar su estrecha relación con el Dr. Waters para la creación del sistema "To and Fro", con el Dr. Guedel para le creación de las cánulas faríngeas (conocidas en Chile como cánulas mayo), con el Dr. Magill para la creación de tubos endotraqueales, entre otros. El Dr. Frías encontró un terreno fértil para su sentido práctico.

La Foregger Company, que ya llevaba varios años trabajando en el desarrollo de máquinas de anestesia, había visto cómo el tamaño de las máquinas iba en aumento, creando verdaderas estaciones de trabajo tal como las concebimos hoy en día. Sin embargo, vieron que era necesario contar con una máquina más portátil dadas las necesidades de anestesiólogos que trabajaban en condiciones de aislamiento (toda esta información la obtenían de los congresos de anestesiología que se realizaban en distintas partes de Estados Unidos).

Así fue como se creó la "Midget" en 1924. Una máquina portátil, con cilindros pequeños y que tenía un muy bajo consumo debido a que tenía incorporados flujómetros de hasta $1.000 \mathrm{cc} / \mathrm{min}$ y absorbedores de $\mathrm{CO}_{2}$. Esta se vendía en una maleta de cuero y con un soporte con ruedas para su desplazamiento en caso necesario. La original traía 2 cilindros tipo AA y 2 cilindros de óxido nitroso. Esta máquina fue hecha en base a las especificaciones del Dr. Ralph Waters y entre sus características destacaban su peso (aproximadamente 13 kilos), y sus cilindros que aportaban 180 litros de óxido nitroso cada uno y 56 litros de oxígeno cada uno también.

Su precio variaba según los accesorios que se agregaban, pero en general rondaba los 150 a 200 dólares de la época.

La Foregger siguió personalizando esta máquina según los requerimientos de los distintos anestesiólogos que se acercaron a la empresa para mostrar sus diseños. Así tenemos la "Miur Midget" (adaptada a las especificaciones del Dr. Royden Muir), la "Australian Midget" (adaptada a las necesidades del Dr. Gilbert Troup, de Australia) y la "Chilean Midget". Es probable que existieran otras máquinas personalizadas, pero como tales estas son las modificadas que aparecen en los catálogos de la compañía.

La "Chilean Midget" estaba pensada para tener una máquina que fuera fácilmente desplazable, de pabellón en pabellón, en un país como Chile de 1935- 
38. Esta máquina tenía dos cilindros de oxígeno y dos de ciclopropano, sin óxido nitroso.

Y así fue como comenzó esta historia. "La Chilean Midget" fue vendida por la empresa por varios años, especialmente en situaciones en las que se requiriese movilidad y poco consumo. Actualmente, existe una en el Museo de Historia de la Medicina de la Universidad de Chile y otra en el Museo de la Asociación de Anestesia Analgesia y Reanimación de Buenos Aires.

\section{Vuelta a Chile}

La vuelta a Chile en 1936 fue breve. El 10 de junio de 1936 el Dr. Frías, aún como ayudante de la Clínica Quirúrgica del profesor don Lucas Sierra, fue comisionado para asistir al curso "Adelantos de la oxigenoterapia, de la carbodioxiterapia y la anestesia general con gases" que se impartió en la Universidad de Buenos Aires. El curso duró tres meses lo que le permitió estrechar lazos, contactarse con anestesiólogos de Europa y Estados Unidos que vinieron a impartir el curso y adquirir práctica con el uso del ciclopropano (que no había logrado realizar durante su viaje a Nueva York).

Además, hizo las gestiones para importar una buena cantidad de este gas para su uso en Chile y trajo nuevas máquinas de anestesia.

Como anécdota destacable su hija relata las vicisitudes que tuvo que pasar Don Ernesto para ingresar las máquinas de anestesia al país. Cuenta que cuando llegaron a Valparaíso, el oficial de aduana, al no entender el uso de las máquinas y por sus colores y perillas brillantes, decidió que lo más probable es que fueran artículos de lujo, importados para uso personal. Por lo tanto, procedió a aplicar el cobro de un impuesto al lujo. El valor era tan alto que don Ernesto prefirió seguir con las máquinas al puerto de Talcahuano, en donde pudo ingresarlas al país sin la carga impositiva que se había hecho en Valparaíso.

Sin embargo, la historia no termina ahí. Se solicitó su asistencia como anestesiólogo en el hospital Las Higueras de Talcahuano para una cirugía de tórax. Como él disponía de una máquina de anestesia con un circuito cerrado y tubos endotraqueales con cuff, se pudo realizar la apertura de la caja torácica sin problemas. Por eso la primera cirugía de tórax abierto con circuito cerrado de anestesia se realizó en provincia y no en Santiago.

\section{Servicio de Anestesiología hospital del Salvador}

En septiembre de 1941 el Dr. Frías se integró al
Servicio de Cirugía del Hospital del Salvador como Jefe del Departamento de Anestesiología. Además de él, el Dr. Tomás Cooper también integró este departamento como ayudante. Desde este momento, hasta su jubilación, se desempeñó como anestesiólogo en este centro asistencial.

En 1944 ocurrió un accidente en el hospital. Un médico trató de trasvasijar oxígeno a un cilindro de ciclopropano provocando una explosión en la que falleció el doctor y otro, un anestesiólogo, resultó mutilado.

A raíz de este accidente, la Junta de Beneficencia, que estaba a cargo de la administración de los hospitales de Chile, decidió crear una instancia que entrenara en anestesiología a las personas que se desempeñaran en la especialidad en los hospitales nacionales.

Así nació la primera escuela organizada de anestesiología de Chile. El postulante debía pasar 6 meses en instrucción y al finalizar el curso hacer una tesis en la especialidad que, tras ser aprobada, le confería el título de Anestesiólogo de Beneficencia. La organización del curso estuvo a cargo del Jefe del Servicio de Cirugía, el Dr. Félix de Amesti, el Jefe del Departamento de Anestesiología, el Dr. Ernesto Frías y el Dr. Thomas Cooper, primer ayudante del ramo.

Entre los médicos que fueron formados en esta instancia se cuentan destacados anestesiólogos como el Dr. Mario Folch Ángulo, quien junto a un grupo de médicos crearía el Servicio de Anestesiología en el Hospital Clínico de la Universidad de Chile en 1944, el Dr. Raúl Mena Jeria, Dr. Luis Cabrera G, Dr. Felipe

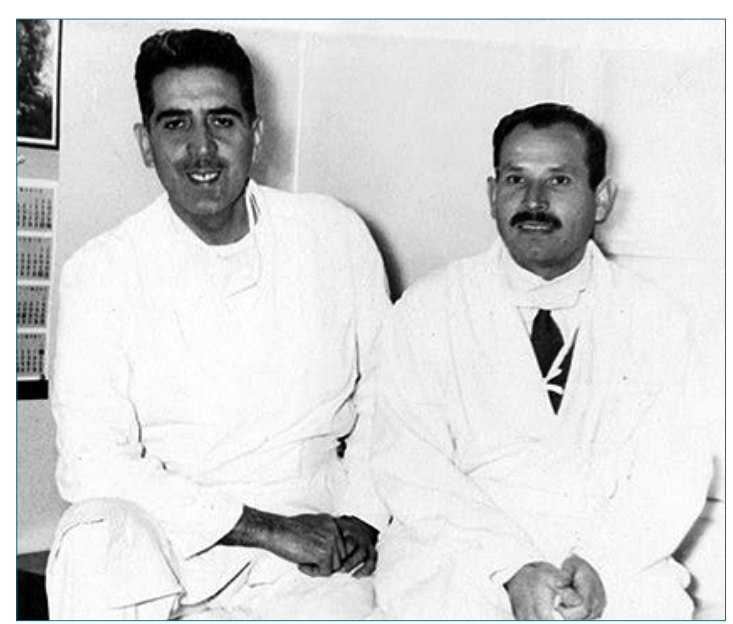

Figura 6. Dr. Frías en el Departamento de Anestesia. Hospital del Salvador (con permiso). 
Olivarí, el Dr. Pedro Escobar, el Dr. Rubén Leiva, entre otros.

No solamente se entrenaba médicos. También matronas e incluso religiosas recibieron formación en anestesia y recibieron su certificado de Anestesista de Beneficencia.

Este centro fue el germen, la raíz de la anestesiología chilena y el sitial que ocupa ahora la especialidad le debe sus orígenes a estos humildes pero sinceros esfuerzos por darle mayor seguridad a los pacientes que eran sometidos a cirugías.

\section{Actividad gremial}

El 16 de octubre de 1946, 100 años después de la primera administración pública exitosa de una anestesia con éter administrada por el odontólogo Thomas G Morton en el Hospital General de Massachusetts, se fundó la Sociedad Chilena de Anestesiología. El Dr. Frías fue uno de sus miembros fundadores y su primer presidente. Desde ahí, fue un gran impulsor de la actividad anestesiológica para organizar y mejorar las condiciones de la especialidad en nuestro país. Junto a estas actividades se desempeñó también como responsable de la comisión que evaluó el trágico accidente ocurrido en el pabellón del Hospital de niños Manuel Arriarán el 6 de mayo de 1963, en el que murieron los doctores Ana María Juricic Villalón (anestesiólogo), Jaime Palominos Zúñiga, Mario Torres Kay (anestesiólogo) y Enrique Zabalaga a raíz de una explosión asociada al uso de ciclopropano. Presidió la comisión que luego de investigar la tragedia y sus razones, creó nuevas recomendaciones que hicieron más seguros los pabellones quirúrgicos y que fueron aplicadas en todo Chile.

\section{Actividad privada}

Además de trabajar en Clínicas privadas con distintos equipos quirúrgicos, el Dr. Frías fundó la empresa Oximed en 1962, como una manera de organizar algo que llevaba mucho tiempo realizando de manera altruista. La necesidad de ofrecer oxígeno en los domicilios, a los pacientes que eran dados de alta desde los distintos centros hospitalarios y que necesitaban oxigenoterapia.

Si bien, sus principios fueron humildes, luego de más de 20 años de funcionamiento y asociado a la aparición en Chile de los sistemas de hospitalización domiciliaria, este tipo de terapia se hizo más habitual, siendo pionero en esta área de manejo de los pacientes respiratorios crónicos.

De más está decir, que no se hizo millonario. Sin embargo, siempre estuvo presente la necesidad de hacer un aporte práctico a la salud de la población.

\section{En fin...}

Ernesto Frías Meneses se mantuvo en constante movimiento. Hizo varios viajes a Estados Unidos para mantenerse al tanto de los avances en anestesiología y fue un incansable promotor de congresos en Latinoamérica, especialmente en Argentina, en donde aún se lo recuerda con cariño. Fue miembro de distintas Sociedades de Anestesiología de Latinoamérica, de la de Argentina e incluso de la de Cuba. Fue Fellow del International College of Anesthetists y presidente de distintos congresos de anestesiología en Latinoamérica.

El Dr. Ernesto Frías Meneses falleció el 20 de junio de 1977 a raíz de un cáncer de colon, en Houston, Texas, luego de darse cuenta él mismo de la gravedad de su situación.

Dejó un legado que persiste hasta hoy y al que debemos más de lo que creemos, no solo los anestesiólogos, sino todo médico que se precie de tal.

Como dijo Winston Churchill, muchos le debemos mucho a unos pocos. Uno de ellos es Ernesto Frías. Un hombre que fue incansable, inquieto, afable y exigente. Un hombre que a lo largo de su vida aplicó cada cosa que fue aprendiendo para lograr un beneficio inmediato de sus pacientes. Un hombre que formó a excelentes profesionales que crearon la Anestesiología académica moderna del Chile de hoy.

Es necesario detenernos y recordar sus logros para darnos cuenta de que no estamos parados hoy sobre el aire. Estamos en donde estamos, gracias a los esfuerzos de gigantes que forjaron las bases de nuestro presente.

Agradecemos a la familia Frías, especialmente a la Sra. Adriana Frías, quienes generosamente ayudaron con entrevistas, tiempo y documentos familiares para la elaboración de este artículo. 


\section{Referencias}

1. Darrigrandi Isabel. El médico que despertó la anestesiología chilena. Revista Vida Médica Vol. 46 Número 5 Noviembre-Diciembre 1994 págs 66-67.

2. Foregger R. Richard von Foregger, Ph.D., 1872-1960.

Manufacturer of anesthesia equipment. Anesthesiology. 1996 Jan;84(1):190-200. https:// doi.org/10.1097/00000542199601000-00021

PMID:8572332

3. Current Researches in Anesthesia \& Analgesia: March/April 1944 Volume 23 - Issue 2 - ppg 86-87.

4. Ball CM. The Foregger Midget: a machine that traveled. Anesthesiology. 2013 Nov; 119(5):102330. https://doi.org/10.1097/ ALN.0b013e31829b382f
PMID:23838716

5. Barrera F. Tragedia en el hospital de niños Manuel Arriarán: "Porque murieron por nosotros, siguen viviendo entre nosotros". Mártires de la Cirugía Infantil chilena. Rev Chil Pediatr. 2013;84(3):332-8. https://doi.org/10.4067/S037041062013000300014

6. Otaiza E. Historia de la cirugía en el Hospital Salvador.SantiagoChile. Rev Chil Cir. 1994;46:31527.

7. Doyle J. Death of an Anesthesia Company. Can J Anaesth. 2001 Jan;48(1):99-100. https://doi. org/10.1007/BF03019824.

8. Soresi A. James Tayloe Gwathmey, MD, FICA. (Father of modern anesthesia). A tribute. Anesth Analg. 1944 Mar-Apr.

9. Frías E. Resultados alejados de las simpatectomias pelvianas. Tesis para optar al título de Medico.1933 Consultado en www. bibliotecadigital.uchile.cl

10. Bulloug J. Modified Waters's Canister. Anaesthesia 1955; 10:83 11. Venturini AH. Aparato Chilean Midget. Revista Con Anestesia,

11. Asociación de Anestesiología de Buenos Aires. 2001;94:14-15 12. https://www.woodlibrarymuseum.org/museum/item/108/

12. waters-co2-líabsorber Visitada y citada el 22 de Julio 2017. 13. http://www.wikipedia.org en inglés [internet]: "James Tayloe Gwathmey". Editada por ultima vez el 22 de Julio de 2017 a las 17:42. Visitada y citada el 23 de Julio. Disponible en https

13. en.wikipedia.org/wiki/James_Tayloe_Gwathmey 